\title{
PRECISIONES ACERCA DE LA RESPONSABILIDAD DEL ESTADO LEGISLADOR EN COLOMBIA*
}

Abogado de la Universidad Surcolombiana. Coordinador del semillero de investigación 'Aníbal Cardozo Gaitán' de la Facultad de Derecho de la Universidad Surcolombiana.

Oscar Javier Reyes Pinzón

No es posible, pues, dar cabida a reclamaciones de irresponsabilidad del Estado, máxime si se trata de un Estado social de derecho (Art. $1^{\circ}$ de la C. N.) so pretexto de que la acción dañosa es constitutiva del ejercicio de su soberanía; tal recurso no podia jamás servir de excusa o de justificación para que el ejercicio del poder desborde los cauces del derecho, y, en el terreno de lo arbitrario, produzca impunemente daños antijurídicos a los asociados".

\section{Consejo de Estado, Sala de lo Contencioso Administrativo, Sección Tercera. \\ Sentencia de 2 de febrero de 1995, C.P: JUAN DE DIOS MONTES HERNÁNDEZ.}

\section{RESUMEN}

En Colombia existen antecedentes jurisprudenciales y doctrinales que permiten ir elaborando y estructurando la responsabilidad del Estado legislador. Por ser ésta una clase de responsabilidad extracontractual del Estado, para fines prácticos, es necesario abordar el tema bajo los elementos de la responsabilidad del Estado: el hecho o la actuación del Estado (Ley vigente, Ley declarada inconstitucional con efecto retroactivo, omisión legislativa relativa) el daño y el nexo causal entre el hecho o la actuación del Estado y el daño; y como elemento adicional, el fundamento del deber reparatorio, elemento que contribuye a establecer los títulos de imputación, aplicables en cada caso por el juez (Falla del servicio legislativo, Daño especial).

\section{PALABRAS CLAVES}

Responsabilidad extracontractual del Estado, Estado legislador, ley vigente, ley declarada inconstitucional, omisión legislativa relativa, daño antijurídico, falla del servicio legislativo, daño especial.

\section{ABSTRACTS}

In Colombia jurisprudential there are and doctrinal precedents that allow to elabora and structure the responsibility of the legislator State. Because this a class of extracontractual responsibility of the State, for practical ends, it is necessary to approach the low topic throug its elements of the: the fact or the performance of the State (effective Law, unconstitutional declared Law with

\footnotetext{
* El título del presente artículo obedece al Capítulo V de la investigación "La responsabilidad del Estado legislador en Colombia", resultado del semillero de investigación 'Aníbal Cardozo Gaitán' de la Facultad de Derecho de la Universidad Surcolombiana, dirigida por el Dr. Diego Omar Perez Salas.
} 
retroactive effect, relative legislative omission) the injure and the causal nexus between the fact or the performance of the State and the, as is an additional element, the foundation of the duty reparatory is an element that contributes to establish the holding of imputation, applicable in each case for the judge faut injure of the Legislative Service, Special Injure.

\section{KEYWORDS}

Extracontractual responsibility of the State, legislating State, effective Law, declared Law unconstitutional, relative legislative Omission, anti legal injure, Fault of The Legislative Service, Special Dảnage.

\section{INTRODUCCIÓN}

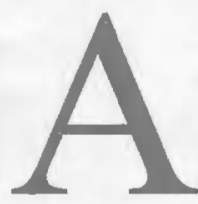

la luz del derecho comparado, la responsabilidaddelEstadolegislador es un tema novedoso; cómo buscar la imputación de daños a la rama del poder más fuerte no es una institución generalizada en todos los países occidentales de gran culto a la soberanía parlamentaria.

El Consejo de Estado francés es quien da el primer paso en este tema, con la sentencia " $\mathrm{L} a$ Fleurette"del 14 de enero de 1938, al imputar responsabilidad al Estagdo por daños ocasionados por la ley, sobrepeniéndose al principio de soberanía parlamentaria y a las características de general y abstracta que encubrían de impunidad a la ley desde la consolidación de los Estados modernos.

Hay tres aspectos relevantes en el mundo occidental que inciden en los cambios del poder soberanodellegisladory que significanla quiebra de los presupuestos sobre los cuales descansa la impunidad del legislador pero, como lo afirma nuestra Corte Constitucional, "la ruptura de tales supuestos no se produjo de manera simultánea, ni significó necesariamente la admisibilidad generalizada de la responsabilidad del Estado legislador."
El primero es el paso evolutivo en la teoría del Estado, que trae consigo la expedición de leyes singulares. El segundo aspecto es la generalización del control de constitucionalidad en gran número de los ordenamientos jurídicos; aunque éste "no es requisito sine qua non para el reconocimiento de la responsabilidad del legislador" ${ }^{\text {. }}$ Y un tercer aspecto relevante es el avance progresista de la doctrina constitucional sobre el paso de constituciones con efectos políticos a constituciones con valor y carácter normativo. Estos tres aspectos son importantes en el trato dado por los países que, de acuerdo a su ordenamiento jurídico y al desenlace de la figura de la responsabilidad estatal, han acogido distintos regímenes y fundamentos para la responsabilidad del Estado legislador.

El presente artículo versa sobre uno de los puntos desarrollados por el semillero de investigación Aníbal Cardozo Gaitán de la Facultad de derecho de la Universidad Surcolombiana en la investigación jurídica denominada "La responsabilidad del Estado legislador en Colombia". Presentamos los elementos, el fundamento y los regímenes aplicables a esta clase de responsabilidad extracontractual del Estado, no sin antes esbozar el problema y la justificación de la investigación en general.

\footnotetext{
${ }_{1}^{1}$ Corte Constitucional, Sentencia C-038 de 2006, Magistrado Ponente: HUMBERTO ANTONIO SIERRA PORTO.

2 Ibidem.
} 


\section{PROBLEMA DE INVESTIGACIŐN}

La jurisprudencia, como fuente del derecho, ha sido la digna encargada en el derecho occidental de aniquilar el viejo paradigma anglosajón de "The King can do not wrong" , equivalente a la irresponsabilidad del Estado y de sus funcionarios.

Hubo de esperarse hasta casi el último cuarto del siglo XIX, para que en Francia, por primera vez se constituyera la piedra angular del derecho administrativo francés y del derecho continental, reconociéndose la responsabilidad del Estado, pero sólo del Estado administrador, en el FALLO BLANCO proferido por el Tribunal de Conflictos en 1873.

Desde el siglo XIX entonces, la responsabilidad delEstadoselimitabaarepararlosdañoscausados extracontrato por el Estado administrador. Los innumerables pronunciamientos del Consejo de Estado, y en su tiempo de la Corte Suprema de Justicia en Colombia, se han dirigido a imputar o exonerar de responsabilidad a la administración.

La sujeción del derecho hacia las otras ramas de poder del Estado fue un avance paulatino, meritorio después de muchos menoscabos cometidos por el uso y abuso del poder estatal, después de teorías jurídico-políticas que acompañaron, y que aún acompañan, el desarrollo del Estado de Derecho, después de teorías constitucionales que reivindican, y contraponen, los derechos de los ciudadanos frente al poder del Estado. El derecho administrativo actual clasifica en tres grandes ramas la responsabilidad extracontractual del Estado: Estado administrador, Estado juez y Estado legislador.

La responsabilidad del Estado legislador en el derecho comparado, desde el fallo francés de 1938 (sentencia La Fleurette), tiene bien ganado su espacio en la doctrina moderna del derecho administrativo. Por ser una institución - novedosa, que busca imputar daños a la rama del poder más fuerte, no es generalizada en todos los países occidentales de gran culto a la soberanía parlamentaria.

En Colombia, la responsabilidad patrimonial del Estado se fortalece por su constitucionalización ${ }^{4}$ dentro de la concepción del Estado social de derecho. Las funciones de la responsabilidad del Estado, -garantía patrimonial, prevención de daños y mecanismo de control del poder estatal $^{5}$ - son más vinculantes en esta tipología de Estado.

Con el artículo 90 de nuestra Constitución Política, y el daño antijurídico como fundamento constitucional de la responsabilidad estatal, el rango de acción de la Responsabilidad Extracontractual del Estado se amplía, su intrínseco carácterjurisprudencial hareconocido que no solamente el Estado-administrador puede ocasionar perjuicios a los ciudadanos, también los puede ocasionar el Estado-juez o el Estado-legislador.

El Consejo de Estado colombiano ha imputado responsabilidad al Estado legislador en dos fallos, demostrando con ello el embrionario desarrollo jurisprudencial y doctrinario que al tema le han dado en Colombia, situación que amerita una construcción doctrinaria que aporte bases teóricas dirigidas a establecer ¿Cuál es el

\footnotetext{
3 "El rey no puede cometer ilícito."

4 Constitución Política de Colombia de 1991. Artículo 90: "El Estado responderá patrimonialmente por los daños antijurídicos que le sean imputables, causados por la acción o la omisión de las autoridades públicas. En el evento de ser condenado el Estado a la reparación patrimonial de uno de tales daños que haya sido consecuencia de la conducta dolosa o gravemente culposa de un agente suyo, aquel deberá repetir contra este."

${ }^{5}$ SAAVEDRA BECERRA, Ramiro. La responsabilidad extracontractual de la administración pública, $1^{\circ}$ Edición, Bogotá, Ediciones jurídicas Gustavo Ibáñez, 2005, pp. 183 a 200.
}

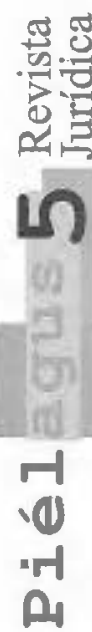


fundamento de la responsabilidad del Estado legislador? ¿Cuál es el régimen aplicable o cuales serían las causales de imputación al Estado por daños causados por la ley? ¿Cómo es el trato al concepto de Daño Antijurídico en ésta especie de Responsabilidad estatal? ¿Cuáles serían las posibles hipótesis en que el Estado - legislador puede causar daños a los ciudadanos? Y muchas otras preguntas que apunten a establecer como problema de investigación, ¿Cuales son los soportes constitucionales, doctrinales y jurisprudenciales en nuestro ordenamiento jurídico para obligar al Estado Colombiano a indemnizar los daños y perjuicios que con ocasión de la actividad legislativa resulten a los particulares?

\section{JUSTIFICACIÓN}

La responsabilidad del Estado legislador es un tema bastante novedoso en nuestra doctrina colombiana. Sobre ello, MANUEL ALBERTO MORALES afirma:

“(...) de lo que ne dudo es que en nuestro medio el tema hiace parte de aquellos tabú, porque se menciona pero en voz baja, la cátedra no lo asume en su verdadera extensión y contenido, la doctrina se refiere al mismo en forma tangencial y los pronunciamientos de la jurisdicción contencioso administrativa son escasos, por no decir que exóticos, para no incurrir en una imprecisión."

Este tema implica el rompimiento de paradigmas imperantes del Estado de derecho. El paradigma de la soberanía parlamentaria igual a irresponsabilidad, y las características de general, impersonal y abstracta de la ley, permitieron en el Estado moderno que al ser la ley expresión de la voluntad general, incluía también la del propio damnificado, que de tal modo no podía fundar ningún tipo de reclamo. En tal sentido, la irr ponsabilidad del Estado por los daños causad : $\mathrm{s}$ por la función legislativa ha sido admitida como un dogma, por ello, la responsabilidad del Estado legislador en Colombia implica acentuar el Estado social de derecho, implica sujetar más el Estado al Derecho.

Elaborar una construcción doctrinaria que aporte bases teóricas dirigidas a establecer cuál es el fundamento de la responsabilidad del Estado - legislador, o cuales serían.las causales de imputación al Estado por daños căusados por la ley, significa dar instrumentos sustanciales doctrinarios de defensa al ciudadano víctima por el hecho de la ley; significa desarrollar un nuevo capítulo dentro de la institución de la Responsabilidad Extracontractual del Estado; significa ampliar la interpretación del artículo 90 constitucional; significa otorgar responsabilidad a nuestro Estado frente a sus ciudadanos.

\section{RESULTADOS}

\subsection{Elementos de la Responsabilidad del Estado Legislador.}

Loselementosestructuralesdelaresponsabilidad, en sentido genérico, son tres: la actuación de un sujeto, el daño y la existencia de un nexo causal entre el daño y la actuación del sujeto. En el derecho civil colombiano, se suma como elemento adicional la culpa del actor del daño, puesto que por regla general la responsabilidad civil extracontractual en Colombia se basa en la culpa. ${ }^{7}$

\footnotetext{
${ }^{6}$ MORALES TÁMARA, Manuel Alberto. "Responsabilidad patrimonial del Estado legislador", A.A.V.V. II Jornadas de derecho constitucional y administrativo, Bogotá, Universidad Externado de Colombia, 2002, p. 373.

${ }^{7}$ TAMAYO JARAMILLO, Javier. De la responsabilidad civil, Tomo I, Bogotá, Temis, 1999, pp. 169 a 272. También: MARTÍNEZ RAVE, Gilberto y MARTÍNEZ TAMAYO, Catalina. Responsabilidad civil extracontractual, $11^{\mathrm{a}}$ ed., Temis, 2003, pp. 18 a 20 y 78 a 82.
} 
En el marco de la responsabilidad del Estado, los tres elementos son el hecho o la actuación del Estado, el daño ${ }^{8}$ y el nexo causal entre el hecho o la actuación del Estado y el daño. Un elemento adicional en el derecho administrativo es el fundamento del deber reparatorio, elemento que contribuye a establecer el régimen de responsabilidad, o título de imputación, aplicable en cada caso por el juez, trayendo consigo unos presupuestos propios.

No pretendemos en este aparte desarrollar en su totalidad estos elementos en el gran instituto de la responsabilidad del Estado, sólo los referiremos dentro de la responsabilidad del Estado legislador.

\section{a. Hecho o conducta generadora del Daño}

La mayoría de la doctrina colombiana centra el soporte de este elemento de la responsabilidad extracontractual del Estado en la consagración legal del Código Contencioso Administrativo $^{9}$ (C.C.A. en adelante) en su artículo $86^{10}$.reduciéndolo a la mera conducta administrativa:

\section{"ACCTON DE REPARACTON DIRECTA.}

La persona interesada podrá demandar directamente la reparación del daño cuando la causa sea un hecho, una omisión, una operación administrativa o la ocupación temporal o permanente de inmueble por causa de trabajos públicos o por cualquiera otra causa. (...)" (subrayas nuestras).

Bajo estas subrayas de la norma, presente en nuestros códigos contenciosos administrativos desde $1941^{11}$, los contenciosos de responsabilidad estatal se derivan de las conductas administrativas originadas en hechos $\mathrm{u}$ omisiones que se traducen en daños para los administrados, de manera que pareciera que la norma, con el recorrido histórico que posee, ha contribuido con la irresponsabilidad del Estado juez y del Estado legislador.

Sin embargo, esta lectura restrictiva del artículo 86 del C.C.A. fue desplazada por una interpretación extensiva de conformidad con la cual las expresiones "hecho" y "omisión" no se restringen a las imputables a una autoridad administrativa, sino que incluirían, además, la actuación de los órganos del Estado que cumplen funciones judiciales y funciones legislativas.

\section{El Consejo de Estado ha acogido y acoge} esta interpretación al tramitar acciones de reparación directa por daños ocasionados de hecho $u$ omisiones del poder judicial ${ }^{12}$-desde antes de la Constitución Política de 1991 y más ahora con la Ley Estatutaria de Administración

\footnotetext{
${ }^{8}$ RODRIGUEZ R, Libardo. Derecho administrativo general y colombiano, 12a ed., Bogotá, Temis, 2000, pp. 389 a 392. También: JORGE ENRIQUE AYALA. Elementos de derecho administrativo, $1^{a}$ Edición, Bogotá, Ediciones Doctrina Y Ley Ltda., 1999, pp. 666 a 684.

${ }^{9}$ DECRETO 01 del 2 de enero de 1984. Diario Oficial No. 36.439, del 10 de enero de 1984. Por el cual se reforma el Código Contencioso Administrativo.

${ }^{10}$ Subrogado por el artículo 31 de la Ley 446 de 1998.

${ }^{11}$ Ley 167 de 1941. ARTÍCULO 68: También puede pedirse el restablecimiento del derecho cuando la causa de la violación es un hecho o una operación administrativa. En este caso no será necesario ejercitar la acción de nulidad, sino demandar directamente de la administración las indemnizaciones o prestaciones correspondientes. (subrayas nuestras).

${ }^{12}$ Texto original del Decreto 1 de 1984: ARTÍCULO 86. ACCION DE REPARACIONDIRECTAY CUMPLIMIENTO. La persona que acredite interés podrá pedir directamente el restablecimiento del derecho, la reparación del daño, el cumplimiento de un deber que la administración elude, o la devolución de lo indebidamente pagado, cuando la causa de la petición sea un hecho, o un acto administrativo para cuya prueba haya grave dificultad. (subrayas nuestras).

Texto subrogado por el artículo 16 del Decreto 2304 de 1989: ARTíCULO 86. ACCION DE REPARACION DIRECTA. La persona interesada podrá demandar directamente la reparación del daño cuando la causa de la petición sea un hecho, una omisión, una operación administrativa o la ocupación temporal o permanente de inmueble por causa de trabajos públicos. (subrayas nuestras).
} 
de justicia de $1996^{13}$ - y al tramitar acciones de reparación directa por daños ocasionados de hecho $\mathrm{u}$ omisiones del poder legislativo -como en las sentencias del 25 de agosto y del 8 de septiembre de 1998 de la Sala Plena, y en la sentencias del 26 de septiembre de 2002 y el auto del 15 de mayo de 2003 de la Sección Tercera-. Esta es una interpretación del artículo 86 del E.C.A. acorde con el artículo 90 de la Constitución, disposición constitucional que establece la obligación de reparar los daños antijurídicos provenientes de cualquier autoridad pública, corroborada recientemente por la Corte Constitucional. ${ }^{14}$

Establecido el soporte constitucional y legal de la actuación legislativa como hecho que origina daños, entraremos a identificar el hecho causante del daño.

GUSTAVO PENAGOS, en El daño antijurídico, citando a Marienhoff expresa:

"La doctrina moderna admite la reparación patrimonial del Estado-legislador, tanto por aplicación de una ley válida como inválida. (...), pues también en este ámbito rige el principio de que el comportamiento dañoso o lesivo del Estado es posible que derive del ejercicio «inválido» (Vgr., ley «inconstitucional») o del ejercicio «normal» de sus potestades legales (Vgr., ley que monopoliza una actividad - lícita, desde luego- que hasta entonces era de libre ejercicio por los administrados)." 15

Partiendo del aporte del autor colombiano, el daño que el Estado ocasione en su función legislativa puede resultar de:

- Una ley vigente.

- Una ley inconstitucional.

- Una omisión legislativa.

En este sentido, los hechos o actuaciones, en esta clase de responsabilidad, tienen que ver más allá que con las meras leyes, cơn la función legislativa de esa rama del poder del Estado.

Esta identificación e individualización de los hechos o actuaciones del legislador que genera los daños son necesarias e importantes para efectos de la caducidad de la acción de reparación directa. ${ }^{16}$

\section{- Ley vigente.}

Cuando el acto del legislador causante del daño es una ley vigente, se entiende en cada caso, que a la ley ya se le realizó el estudio previo de constitucionalidad por la Corte Constitucional antes de entrar en vigencia ${ }^{17}$, o el estudio

${ }^{13}$ CAPÍTULO VI. DE LA RESPONSABILIDAD DEL ESTADO Y DE SUS FUNCIONARIOS Y EMPLEADOS JUDICIALES. ARTICULO 65. DE LA RESPONSABILIDAD DEL ESTADO. El Estado responderá patrimonialmente por los daños antijurídicos que le sean imputables, causados por la acción o la omisión de sus agentes judiciales.

En los términos del inciso anterior el Estado responderá por el defectuoso funcionamiento de la administración de justicia, por el error jurisdiccional y por la privación injusta de la libertad.

${ }_{15}^{14}$ Corte Constitucional. Sentencia C-038 de 2006, M.P.: HUMBERTO ANTONIO SIERRA PORTO.

${ }^{15}$ PENAGOS, Gustavo. El daño antijurídico. aplicación del principio iura novit curia, Bogotá, Librería Doctrina Y Ley, 1997, pp. 238 y 239.

16 ARTICULO 136. CADUCIDAD DE LAS ACCIONES. <Subrogado por el artículo 44 de la Ley 446 de 1998 . El nuevo texto es el siguiente:>

(...)

8. la de reparación directa caducará al vencimiento del plazo de dos (2) años, contados a partir del día siguiente del acaecimiento del hecho, omisión u operación administrativa o de ocurrida la ocupación temporal o permanente del inmueble de propiedad ajena por causa de trabajo público o por cualquier otra causa.

${ }^{17} \mathrm{El}$ control previo de constitucionalidad recae sobre los siguientes asuntos: objeciones presidenciales a proyectos de ley, formuladas por razones de inconstitucionalidad (artículo 167 C.P.); la decisión, antes del pronunciamiento popular, sobre la constitucionalidad de la convocatoria a un referendo o a una asamblea nacional constituyente para reformar la Constitución, sólo de forma (artículos 3778, 155 y 376 C.P.); proyectos de leyes estatutarias (artículos 241 , num. 8, y 153 C.P); y revisión previa de los tratados internacionales y de las leyes que los aprueban (artículo 241, num. 10 C.P.). 
fue posterior ${ }^{18}$, o simplemente aún no se ha demandado su constitucionalidad. En cualquiera de estos eventos, la ley debe ser la causa de un daño antijurídico sobre el ciudadano víctima, afectando un derecho adquirido o afectando la protección de la confianza legítima sobre una situación jurídica, generando una carga especial y anormal sobre ella (debido a que la norma por ser legal y legítima es una carga pública que en principio se reparte a todos los ciudadanos por igual) que, bajo la concepción de nuestro Estado Social de Derecho, de nuestro constitucionalismo y de la teoría moderna del Derecho Administrativo, resulta impensable que las consecuencias dañosas de una ley recaigan sobre ese ciudadano.

Como ejemplo de daños causados por una ley constitucional en Colombia tenemos a los dos únicos $\operatorname{casos}^{19}$, en los que el Consejo de Estado colombiano ha declarado responsable al Estado legislador ${ }^{20}$, en estos se demanda a la Nación, para que se le declare responsable de los perjuicios sufridos como consecuencia de la ley que estableció la inmunidad de jurisdicción diplomática $^{21}$, por cuya aplicación se les impidió a los actores accionar para obtener la reparación de daños causados por un agente diplomático en un accidente de tránsito.

\section{- Omisión legislativa.}

Cuando el acto del legislador causante del daño es una omisión legislativa, la situación hay que tratarla con base en los siguientes postulados conceptuales y doctrinales.

El Consejo de Estado desestimó la responsabilidad del Estado legisłador por omisión legislativa en el fallo del $1^{\circ}$ de noviembre de $2001^{22}$, esta Corporación expresó que una omisión legislativa implica la existencia de una obligación de legislar concreta proveniente de la Constitución, no solo en materia sino en tiempo. Por ello, los encargos específicos que el constituyente da al legislador para que los desarrolle de manera exhaustiva son los que

${ }^{18}$ Los asuntos materia de control constitucional posterior son los siguientes: Por vía de acción pública están las reformas constitucionales por vicios de procedimiento (cualquiera sea la modalidad, artículo 241 , num. 1 C.P.), las leyes proferidas por el Congreso (artículo 241, num. 4 C.P.), los decretos leyes dictados por el Presidente de la República en desarrollo de facultades extraordinarias concedidas por el Congreso según el artículo 150, num. 10 C.P. (artículo 241, num. 5 C.P.) y el decreto dictado por el Presidente en el caso del artículo 341 C.P. para adoptar el Plan de Inversiones Públicas cuando hayan transcurridos tres meses desde la presentación del proyecto sin que el Congreso lo haya adoptado. Por vía automática están los referendos sobre leyes y las consultas populares y plebiscitos de orden nacional, estos sólo por procedimiento (artículo 241, num. 3 C.P.) y los decretos dictados por el Presidente en uso de las atribuciones propias de los estados de excepción (artículos 212, 213 y 215 C.P.).

19 Consejo de Estado, Sala Plena. Sentencia de 25 de Agosto de 1998, Exp. IJ001, Actor: Vitelvina Rojas Robles, C.P.: JESUS MARIA CARRILLO BALLESTEROS; y Consejo de Estado, Sala Plena. Sentencia de 8 de septiembre de 1998, Exp. IJ002, Actor: Leonor Judith Fandiño de Tarazona y otros, C.P.: DANIEL SUÁREZ HERNÁNDEZ.

${ }_{20}$ Estas sentencias son referenciadas en nuestras fuentes doctrinales consultadas en: SAAVEDRA BECERRA, Ramiro. La responsabilidad extracontractual...op., cit., pp. 452 Y 455; ALIER HERNANDEZ "Responsabilidad extracontractual del Estado colombiano", Revista Derechos y Valores, s.f., Bogotá, Universidad Militar Nueva Granada, pp. 137 y 141; CAROLINA ARENAS URIBE y MARIANGELA JMENEZ USCATEGUI. La responsabilidad del Estado por el hecho del legislador, Trabajo de Tesis, Bogotá, Pontificia Universidad Javeriana, 2001, pp. 81 y 83; PAOLA FRANCO RODRIGUEZ Y MANUEL EDUARDO GONGORA MERA. La responsabilidad del Estado Legislador en los eventos de sentencias moduladas. Trabajo de Tesis, Bogotá, Pontificia Universidad Javeriana, 2001, pp. 84 y 89; JESUS MARIA CARRILLO BALLESTEROS. "Las principales doctrinas del Consejo de Estado colombiano", A.A.V.V. Historia y perspectivas de la jurisdicción administrativa en Francia y en América Latina, Coloquio conmemorativo del bicentenario del Consejo de Estado francés, Bogotá, Temis, 1999, p. 128.; MANUEL ALBERTO MORALES TÁMARA. "Responsabilidad patrimonial del...", art., cit., pp. 399 y 404.; y GERMAN EDUARDO QUINTERO ROJAS. "De la responsabilidad del Estado legislador", Revista del programa de derecho, No. 8, 2004, Ibagué, Coruniversitaria.

21 Esta es la ley 6 de 1972, la cual aprueba la Convención de Viena sobre Relaciones Diplomáticas, ley que por referirse a una Convención internacional tuvo su control previo de constitucionalidad.

${ }_{22}$ Consejo de Estado, Sección Tercera. Sentencia de $1^{\circ}$ de noviembre de 2001, C.P.: MARÍA ELENA GIRALDO GÓMEZ, Actor: Oswaldo Patascoy Martínez. 
pueden ser objeto de la omisión legislativa ${ }^{23}$, pues esta figura no tiene cabida en la obligación genérica que tiene el legislador de hacer leyes; al respecto dice el citado fallo:

\section{"Las funciones legislativas que la Constitución Política de 1991 otorgó al Congreso en los artículos 114 y 150, no se delimitaroneneltiempoynoestánconcebidas desde un punto de vista obligacional. Por ello la no producción de normas legales por el Congreso, y para desarrollar la Constitución, no está sancionada jurídicamente con un efecto..."}

De esta manera sólo se puede pretender la indemnización de daños causados por el legislador cuando no ha legislado preceptos constitucionales con un sentido obligacional en contenido y en tiempo, con su determinada consecuencia jurídica. ${ }^{24}$

Sin embargo, creemos que la Corte Constitucional, como guardiana de la Carta por voluntad del constituyente puede jugar un papel muy importante en estos casos. Esta Corporación ha éstatuido la clasificación doctrinaria de omisiones legislativas entre omisiones absolutas y omisiones relativas ${ }^{25}$ en los siguientes términos:

"El legislador puede violar los deberes que le impone la Constitución de las siguientes maneras: cuando no produce ningún precepto encaminado a ejecutar el deber concreto que le ha impuesto la Constitución; cuando en cumplimiento del deber impuesto por la Constitución, favorece a ciertos grupos, perjudicando a otros; cuando en desarrollo de ese mismo deber, el legislador en forma expresa o tácita, excluye a un grupo de ciudadanos de los beneficios que otorga al resto; cuando el legislador al regular o construir una institución omite una condición o un ingrediente que, de acuerdo con la Constitución, sería exigencia esencial para armonizar con ella."26

En el primer caso estamos frente a una omisión legislativa absoluta por cuanto falta la disposición de desarrollo legislativo de un determinado precepto constitucional; en los restantes, se presenta una omisión legislativa relativa porque si bien el legislador ha expedido la ley, en ella solamente ha regulado algunas relaciones dejando por fuera otros supuestos análogos, con clara violación del principio de igualdad.

El aporte de la Corte Constitucional sobre el tema puede resultar significativo cuando en un estudio de constitucionalidad de una norma encuentra que existe en ella una omisión legislativa relativa, y exhorta al Congreso para que la complemente o la corrija en un tiempo

\footnotetext{
${ }^{23}$ ARENAS URIBE, Carolina y JIMENEZ USCATEGUI, Mariangela. La responsabilidad del Estado por el hecho..., op. cit., p. 56.

${ }^{24}$ El fallo del Consejo de Estado expresa la única disposición constitucional con sentido obligacional en contenido y en tiempo: "Sólo la competencia del Congreso, prevista en el inciso $3^{\circ}$ del artículo 341 Constitucional sí tiene una consecuencia jurídica, cuando no se ejercita en tiempo y se relaciona en la expedición del Plan Nacional de Inversiones. En ese caso la Constitución sí sanciona la omisión legislativa con la pérdida de la competencia material del Congreso en ese año, por el no ejercicio de la función en ese término de tres meses, para expedir la ley de aprobación al Plan Nacional de Inversiones Públicas, y además transmite esa competencia al Gobierno nacional." Consejo de Estado, Sentencia de $1^{\circ}$ de noviembre de 2001, loc.cit.

25 "Esta distinción se debe a WESEL, para quien existe omisión absoluta cuando "falta cualquier norma aplicativa del precepto constitucional"; y omisión relativa, cuando "existe una omisión parcial que disciplina sólo algunas de las relaciones y no otras análogas, con la consiguiente lesión del principio de igualdad". CAROLINA ARENAS URIBE y MARIANGELA JIMENEZ USCATEGUI. La responsabilidad del Estado por el hecho... op., cit., p. 57.

${ }^{26}$ Corte Constitucional, Sala Plena. Sentencia C-543 de 16 de octubre de 1996, Expediente D-1286, Demandante: Hugo Alberto Marín, M.P.: CARLOS GAVIRIA DIAZ.
} 
establecido por ella en su fallo ${ }^{27}$, de manera que si el Congreso no legisla sobre la materia para mejorar la regulación como se lo aconseja la Corte Constitucional en el tiempo, se presenta una negligencia del legislador en producir o adeçuar la norma en contenido y tiempo, y degeneraría en una carga desigual sobre los ciudadanos discriminados, meritorio de un hecho dañoso del Estado legislador.

\section{- Ley declarada inconstitucional.}

Cuando el acto del legislador causante del daño es una ley declarada inconstitucional ${ }^{28}$, hay que tener presente el fallo de la Corte Constitucional que declaró inexequible la norma para pretender la reparación de daños causados por ella, y en especial, los efectos de inexequibilidad en el tiempo ${ }^{29}$.

En los casos en que la inexequibilidad del fallo de la Corte Constitucional tenga efectos irretroactivos las situaciones jurídicas concretas que hayan existido durante la vigencia de la norma quedarán indemnes.

Pero en los casos en que la inexequibilidad del fallo de la Corte Constitucional tenga efectos retroactivos, hacia el pasado, implica la anulación de la norma acusada, esto es, la inexistencia ab initio del acto legislativo afectado, asemejándose este efecto de inexequibilidad al efecto de la declaración de nulidad, de manera que las situaciones jurídicas concretas nacidas durante su vigencia quedarán vulnerables.

Tenemos entonces, acorde con nuestro sistema jurídico, democrático y de Estado social de derecho, que sólo es posible pretender acción de reparación por daños causados por ley inconstitucional cuando su inexequibilidad tiene efectos retroactivos.

Sostiene esta tesis RAMIRO SAAVEDRA al expresar:

\section{"En el caso colombiano la solución lógica es que en los casos en que la inexequibilidad solo tenga efectos para el finturo no puede haber responsabilidad del Estado, ya que las situaciones anteriores al fallo creadas o surgidas bajo el amparo de la ley en cuestión se consideran consolidadas; en cambio, si el fallo dispone efectos retroactivos para la decisión, talresponsabilidadesjuridicamente viable frente a los efectos producidos por la ley inconstitucional ${ }^{30}$}

El Consejo de Estado implícitamente acoge esta tesis en los casos sobre "la concesión del servicio de telefonía móvil celular"31, cuando niega la responsabilidad del Estado a los municipios accionantes que demandan la reparación de daños causados por la ley de presupuesto de 1995 con base en la declaratoria de inexequibilidad contenida en la sentencia C423 de 1995.

27 "Bajo el rótulo de "sentencias exhortativas" hemos encontrado una gran diversidad de sentencias que tienen en común, el señalar el legislador una serie de principios que debe tener en cuenta para elaborar una nueva ley. las diferencias pueden hallarse en su origen y en la forma en que se enuncian, desde los consejos y recomendaciones, hasta las órdenes vinculantes. Según su origen, las sentencias exhortativas pueden ser:

a. Derivadas de la declaratoria de constitucionalidad transitoria de una ley. (...)

b. Derivadas de la declaratoria de mera inconstitucionalidad. (...)

c. Derivadas de una omisión legislativa. (...)".

FRANCO RODRÍGUEZ, Paola y GÓNGORA MERA, Manuel Eduardo. La responsabilidad del Estado legislador ..., op., cit., pp. 171 y 172.

El Consejo de Estado en fallo de la Sección Tercera, mayo 8 de 1995, Exp.8118, C.P.: JUAN DE DIOS MONTES HERNÁNDEZ, reconoce a "la inconstitucionalidad de la ley declarada judicialmente" como título de imputación del daño.

El artículo 45 de la Ley Estatutaria de Administración de Justicia (Ley 270/96), luego del estudio previo de constitucionalidad de la Corte en la sentencia C-037/96 M.P. VLADIMIRO NARANJO MESA, expresa: "Las sentencias que profiera la Corte Constitucional sobre los actos sujetos a su control en los términos del artículo 241 de la Constitución Política, tienen efectos hacia el futuro a menos que la Corte resuelva lo contrario."

30 SAAVEDRA BECERRA, Ramiro. La responsabilidad extracontractual..., op., cit., p. 452.

${ }^{31}$ Consejo de Estado, Sección Tercera. Sentencia de 26 de septiembre de 2002, Radicación número: 25000-23-26-0001997-4458-01(20945), Actor: Municipio de Prado, C.P.: ALIER EDUARDO HERNÁNDEZ ENRÍQUEZ. 
Esta corporación no encuentra estructurado el hecho causante del daño, pues la sentencia de la Corte Constitucional había declarado inexequible de dicha ley, lo referente a la consagración como recursos de capital, la venta del espacio electromagnético para telefonía celular, y en su fallo exhorta al Congreso a expedir una ley que consagre esa venta como

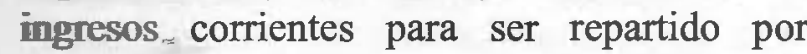
transferencias entre los entes territoriales a partir de la fecha de notificación de dicha sentencia, conteniendo entonces la inexequibilidad un efecto irretroactivo. En este sentido, la ley al ser declarada inconstitucional con efecto hacia el futuro, consolida la situación jurídica existente antes de dicha declaratoria.

También refuerza esta tesis el Consejo de Estado en el Auto del 15 de mayo de $2003^{32}$, cuando resuelve la Sección Tercera el recurso de apelación interpuesto por la parte actora en contra del auto del Tribunal que rechazó una demanda de reparación directa, en la que se solicita la indemnización de daños y perjuicios causados por la expedición ilegal de los Decretos-Ley 1064 y 1065 del 26 de junio de 1999, normas que ordenaban 7a disolución y liquidación de la CAJA DE CREDITO AGRARIO INDUSTRIAL Y MINERO S.S. HOY EN LIQUIDACIÓN, institución donde laboraba para entonces el accionante y por el cual se declaró terminado su contrato indefinido de trabajo.
La Sala ordena admitir la demanda, puesto que "la acción de reparación directa es procedente para obtener la indemnización de perjuicios causados por la aplicación de una norma que ha sido declarada inexequible", y en este caso tales decretos con fuerza de ley fueron declarados inexequibles con efecto retroactivo por la Corte Constitucional en sentencia C- 918/9933. Por ello, la posibilidad de hacer responsable al Estado Legislador por daños causados por leyes inconstitucionales está en manos del efecto del fallo que declare la inexequibilidad de la norma. La Corte Constitucional debe valorar el efecto del fallo.

\section{b. El Daño ${ }^{34}$}

El daño es el elemento en el que existe mayor coincidencia entre la concepción civilista de la responsabilidad contractual y extracontractual y la concepción estatal, a tal punto que, como lo afirma RAMIRO BECERRA, "eso permite estudiar no solo la doctrina y la jurisprudencia propiamente administrativa sino algunas de las soluciones civilistas de la misma índole"35.

Ninguna norma colombiana define el daño. El concepto del daño se ha decantado por la doctrina y la jurisprudencia permitiendo que éste instituto se mantenga en constante evolución ampliando su espectro. Aclarando esto, entendemos entonces por daño "la aminoración patrimonial sufrida por la víctima"36. Por ello, son extensivas

\footnotetext{
${ }^{32}$ Consejo de Estado, Sección Tercera. Auto de 15 de mayo de 2003, Radicación: 76001-23-31-000-2002-191201(23245), Actor: Bernardo Villalba Layton y Otro, C.P.: ALIER EDUARDO HERNÁNDEZ ENRÍQUEZ.

${ }^{33}$ Expresa en tal sentido el RESUELVE: "Decláranse INEXEQUIBLES en su totalidad, a partir de la fecha de su promulgación, los decretos leyes 1064 y 1065 de 1999”. Corte Constitucional, Sala Plena. Sentencia C-918 de 18 de noviembre de 1999, Demandante: Benjamín Ochoa Moreno y Hernando Acosta Pabón, M.P. JOSE GREGORIO HERNANDEZ GALINDO.

${ }^{34}$ La mejor doctrina colombiana, por su desarrollo metodológico y conceptual, es la obra del profesor JUAN CARLOS HENAO. El daño, análisis comparativo de la responsabilidad extracontractual del Estado en derecho colombiano y francés, Bogotá, Universidad Externado de Colombia, 1998.

${ }_{36}$ SAAVEDRA BECERRA, Ramiro. La responsabilidad extracontractual de la administración..., op., cit., p. 593.

36 HENAO, Juan Carlos. El daño, análisis comparativo de la responsabilidad..., p.84.
} 
en nuestro estudio las precisiones sobre el daño que JUAN CARLOS HENAO realiza en su obra $^{37}$ : el daño es el primer elemento a estudiar en un proceso de responsabilidad, el daño es requisito necesario más no suficiente para que se declare lą responsabilidad, el daño debe ser probado por quien lo sufre y el daño deber ser indemnizado plenamente.

En este sentido, en el instituto de la responsabilidad, cualquiera sea su clase, o regímen aplicable, las condiciones de existencia del daño, o sus elementos, son dos: que sea personal y que sea cierto.

En la responsabilidad del Estado legislador, la condición personal del daño implica, al igual que en otras clases de responsabilidad y acorde con la posición actual de la jurisprudencia, que el perjuicio sea sufrido por la persona que solicita la reparación confundiéndose con el legitimado por activa, sea la víctima directa o indirecta ${ }^{38}$; Y la condición cierta del daño tiene que ver con la certeza del daño, esto es, que el perjuicio se considere existente, indiferente que sea pasado o futuro, no debe existir duda alguna sobre su ocurrencia. ${ }^{39}$ A ello se agrega que en principio, los daños originados por actos del legislador pueden contener la gama de tipologías del perjuicio que la doctrina y la jurisprudencia han desarrollado ${ }^{40}$.

\section{c. Nexo Causal}

Entre la actuación imputable al Estado y el daño causado, debe existir una relación de causalidad, esto es, el daño debe ser efecto o resultado de aquella actuación.

Este elemento no varía con las otras clases de responsabilidad estatal, por tanto debe ir más allá del vínculo material, es el vínculo jurídico entre el hecho dañoso y el daño, adoptando las teorías desarrolladas por la doctrina y acogidas por nuestra jurisprudencia ${ }^{47}$ (teoría de la equivalencia de las condiciones ${ }^{42}$ y teoría de la causalidad adecuada ${ }^{43}$ ). De manera que para que exista esa relación de causalidad, el hecho debe ser "actual o próximo, necesario o determinante, $\mathrm{y}$ apto o adecuado para causar determinado daño". ${ }^{4}$

\subsection{El Fundamento de la Responsabilidad del Estado Legislador.}

El fundamento responde a la pregunta de "por qué se debe responder"45, y para dar respuesta a ese interrogante se han desarrollado por la

${ }^{5}$ Para mayor profundidad ver HENAO, Juan Carlos. El daño, análisis comparativo de la responsabilidad..., pp. 33 84.

Thídem, pp. 93 a 105.

Ibídem, pp.129 a 186.

Tbídem, pp.195 a 274.

Una sentencia que desarrolla las teorías adoptadas por la jurisprudencia colombiana es la sentencia del Consejo de Estado, Sección Tercera, de 11 de septiembre de 1999, Exp. 11764, Actor: Olimpo Arias Cedeño y otros, C.P. CARLOS BETANCUR JARAMILLO.

"Cada una de las condiciones que intervienen en la ocurrencia de un hecho debe ser considerada como causa, de tal manera que ninguno de los diversos factores que determinan el resultado tiene una importancia superior a los demás sino que, por el contrario, poseen todos un valor equivalente, pues solo su conjunción hizo posible su resultado". RAMIRO SAAVEDRA BECERRA. La responsabilidad extracontractual de la..., op., cit., p. 538.

Que "parte o presupone la teoría de la equivalencia. Pero alegando la indefinición de aquella, sostiene la necesidad de distinguir entre causas y condiciones, de tal manera que una condición adquiriría la categoría de causa solo cuando de acuerdo con la forma como regular o normalmente se desarrollan los fenómenos conduzca a un resultado, es decir cuando de acuerdo con las reglas generales de la vida, de conformidad con la experiencia general, esa condición sea Ilecuada para la producción de determinado resultado".Ibídem, p. 542.

VALENCIA ZEA, Arturo y ORTÍZ MONSALVE, Alvaro. Derecho civil, T. III, $9^{\text {a }}$ Edición. Bogotá: Editorial Temis, 1998 Pp. 202 a 204.

HENAO, Juan Carlos. "Presentación general de la responsabilidad extracontractual del Estado en Colombia", A. A.V. II Jornadas colombo-venezolana de derecho público, Universidad Externado de Colombia, Bogotá, 1996, 775 . 
doctrina "muchos y muy dispares criterios que en diversas épocas han sido propuestos" ${ }^{\$ 46}$, entre otros están, Teoría de la representación, Teoría organicista, Teoría de la expropiación(Consolo), Teoría de la igualdad o proporcionalidad de las cargas públicas (Teissier), Teoría del seguro contra riesgos sociales (Duguit), Teoría de la equidad (Mayer), Teoría del enriquecimiento sin causa (Hauriou), Teoría de la justicia distributiva, Sacrificio especial, Teoría de la garantía constitucional de los derechos patrimoniales (Spota), Principios propios del Estado de derecho (Marienhoff).

En Colombia, con la decantación jurisprudencial que ha realizado el Consejo de Estado y la Corte Constitucional del artículo 90 de la Constitución Política de 1991, el fundamento de la responsabilidad del Estado es el Daño Antijurídico, al ser concebido el Daño Antijurídico como fundamento de la responsabilidad del Estado no solo extracontractual sino también contractual, y ser bautizada como la 'cláusula general de responsabilidad patrimonial del Estado', no hay duda que el fundamento de la responsabilidad del Estado legisládor, en palabras de la misma Corte Constitucional, "estriba en la noción de daño antijurídico, la cual como se ha reiterado a lo largo de esta decisión descansa en los principios de solidaridad y de igualdad, y no en la idea de la actividad ilícita del legislador, entendida como tal las actuaciones contrarias a la Constitución”,47.

\subsection{Régimen Aplicable a la Responsabilidad del Estado Legislador.}

A nivel jurisprudencial en Colombia, son aplicables en responsabilidad extracontractual del Estado los regímenes de Falla del Servicio, en su modalidad de probada y presunta, el del Daño Especial, el de la Teoría del Riesgo, entre otros.

Referente a los regímenes aplicables a la responsabilidad del Estado legislador BUSTAMANTE LEDESMA, en su obra La responsabilidad extracontractual del Estado, expresa que son dos los regímenes:

"Si una Ley es declarada inconstitucional y con su aplicación se causó un deterioro o lesión a los asociados en sus legítimos derechos, el Estado debe responder por falla en el servicio, con fundamento en las normas constitucionales que protegen los derechos adquiridos con justo tutulo, que no pueden ser vulnerados ni desconocidos por Leyes posteriores."

\section{Y a párrafo seguido:}

"(...) igualmente debe hacerlo cuando el
órgano legislativo expide una Ley que, a
pesar de su carácter general e impersonal,
ocasiona un daño especial, violando de esa
manera el principio de igualdad de todos los
ciudadanos frente a las cargas públicas."48
(cursivas fuera del texto).

El régimen aplicable a la responsabilidad del Estado legislador, depende del hecho causante del daño, esto es, si el daño es causado por una ley vigente, una omisión legislativa relativa, o una ley inconstitucional con efecto retroactivo. En cualquiera de los casos puede existir declaratoria de responsabilidad, pero el régimen es distinto. Frente al primer caso estaríamos ante la probabilidad de aplicar el régimen objetivo de responsabilidad de daño especial, puesto que la actuación del Estado, representada en la ley vigente, es constitucional, legal y legítima.

\footnotetext{
${ }^{46}$ ESCOLA, Hector Jorge. Compendio de derecho administrativo, Vol.II, Buenos Aires, Ediciones Depalma, 1990, p. 1121 .

47 Corte Constitucional, Sentencia C-038 de 2006, M.P.: HUMBERTO ANTONIO SIERRA PORTO.

${ }^{48}$ BUSTAMANTE LEDESMA, Álvaro. La responsabilidad extracontractual del Estado, $1^{\mathrm{a}}$ ed., Bogotá, Leyer Ltda., 1999, p. 115.
} 
Ante los otros dos casos siguientes estaríamos ante el régimen subjetivo de responsabilidad de la Falla del Servicio.

Con base en estas apreciaciones ahondaremos un poce más el tema.

\section{a. Falla del servicio legislativo.}

$\rightarrow$

Antedañoscausadospor leyesinconstitucionales con efecto retroactivo $u$ omisiones legislativas relativas, el regímen a aplicar es la Falla del servicio legislativo.

Por falla del servicio, el Consejo de Estado en fallo del 11 de julio de 1989, advierte que "cuando se habla de falla o falta del servicio no se está haciendo alusión a la vieja noción de servicio público, entendida como 'la actividad de una persona o de un organismo público tendiente a satisfacer una necesidad de interés general', sino a cualquiera actividad que desarrolle la administración o que deba desarrollar por razón de su naturaleza y fines ${ }^{\text {s49 }}$. Por tanto, hablar de "falla del servicio legislativo" 50 , se hace alusión a la actividad legislativa ne como un servicio público, sino como el ejercicio de la función legislativa del Estado.

La falla del servicio legislativo "es toda falta a las obligaciones constitucionales ${ }^{51}$ del legislador en ejercicio de su función legislativa, declarada como tal por sentencia de constitucionalidad", bien sea porque la norma fue declarada inexequible con efectos retroactivos, o porque la Corte en su estudio de constitucionalidad encuentra que existe en la ley sometida a revisión, una omisión legislativa relativa, y exhorta al Congreso a que complemente o la corrija en un tiempo establecido por ella en su fallo y no lo hace.

En cualquiera de los casos anteriores, en la falla del servicio legislativo lo determinante es la sentencia de la Corte Constitucional en la cual realiza el estudio de constitucionalidad, puesto que en ella se encuentra el alcance de su fallo en el tiempo. Para poder predicar la falla del servicio legislativo en un sistema jurídico democrático es necesario que exista un control posterior de la ley, pues el órgano encargado de ello es el único que puede, por obligación de la Constitución, denotar las fallas del legislador al hacer las leyes.

\section{b. Daño Especial.}

Ante daños causados por leyes vigentes o constitucionales, se aplica el regímen del Daño Especial $^{52}$. La ruptura del principio de igualdad de las cargas públicas soportado en la teoría del daño especial, ha sido el fundamento que uso primeramente el Consejo de Estado francés en 1938 para imputar responsabilidad al Estado en la sentencia La Fleurette.

ALVARO BUSTAMANTE explica el soporte doctrinal del daño especial:

"Se compromete la responsabilidad patrimonial de la administración pública cuando ésta, en ejercicio de sus competencias y obrando dentro del marco

\footnotetext{
${ }^{49}$ Consejo de Estado, Sección Tercera. Sentencia de 11 de julio de 1989, Expediente 5446, Actor: Sociedad Vehileasing S.A., C.P. Gustavo de Greiff Restrepo.

${ }^{50}$ Algunos autores usan el término de "Falla del servicio del Legislador", otros de "Falla en la Función Legislativa", otros de "Ilícito Legislativo".

${ }^{51}$ FRANCO RODRÍGUEZ, Paola y GÓNGORA MERA, Manuel Eduardo. La responsabilidad del Estado legislador en los eventos... op., cit., p. 80.

${ }^{52}$. Recordemos que con base en este fundamento el Consejo de Estado colombiano ha declarado por primera vez responsable al Estado colombiano por daños causados por la Ley en las sentencias del 25 de Agosto de 1998 (Expediente IJ-001) y del 8 de septiembre de 1998 (Expediente IJ-002).
} 
de las disposiciones legales, causa con su actuación un perjuicio de naturaleza especial y anormal a un administrado, un daño que excede el sacrificio que el común de los ciudadanos debe normalmente soportar en razón de la peculiar naturaleza de los poderes públicos y de la actuación estatal"53.

El efecto inherente de la ley es imponerse ante el ciudadano. La Ley constitucional, o que se presume su constitucionalidad, es un acto del Estado que en sí mismo genera una carga que deben soportarlas todos los ciudadanos; si tal norma al aplicarse genera sobre ciertas personas una sacrificio especial que desemboca en un perjuicio anormal, rompe o quebranta el principio del equilibrio de las cargas públicas generando al Estado el deber de reparar el daño por causar la Ley un daño especial.

E1 riesgo excepcional no puede ser regímen aplicable en la responsabilidad del Estado legislador, puesto que no hay argumentos para conceptuar que legislar, o más bien, la función legislativa sea una actividad que por sí misma genere peligro o riesgo a los administrados.

\section{CONCLUSIONES}

Como conclusiones del apartado en este artículo tenemos que:

* Los tres elementos estructurales de esta especie de responsabilidad son los mismos de la responsabilidad estatal, el hecho o la actuación del Estado, el daño y el nexo causal entre el hecho o la actuación del Estado y el daño.

* El hecho o conducta del legislador generadora del daño puede resultar de: una ley vigente, una ley inconstitucional con efectos retroactivos y una omisión legislativa relativa.

* Eldañoyelnexocausal,enlaresponsabilidad del Estado legislador, son elementos que no varían en sus condiciones o requisitos de existencia con respecto a las demás clases de la responsabilidad estatal.

* El fundamento de la responsabilidad del Estado legislador es el daño antijurídico.

* Son dos los regímenes aplicables a la responsabilidad del Estado legislador: Falla del servicio legislativo, ante daños causados por leyes inconstitucionales con efecto retroactivou omisiones legislativas relativas; y daño especial ante daños causados por leyes vigentes o constitucionales.

Algunas de otras conclusiones resultado de nuestro trabajo investigativo y que se desarrollan a plenitud en la investigación son:

* Hay tres aspectos relevantes en el mundo occidental que inciden en los cambios del poder soberano del legislador: el paso evolutivo de la teoría del Estado (Estado liberal - Estado intervencionista - Estado social de derecho - Estado constitucional), que trae consigo la expedición de leyes singulares; la generalización del control de constitucionalidad en gran número de los ordenamientos jurídicos; y el avance progresista de la doctrina constitucional sobre el paso de constituciones con efectos políticos a constituciones con valor $y$ carácter normativo.

* La responsabilidad del Estado legislador se predica en Estados que tienen control posterior de constitucionalidad (Italia, Alemania, España, Argentina) y en Estados

${ }^{53}$ BUSTAMANTE LEDESMA, Álvaro. La responsabilidad extracontractual... op., cit., p. 17. 
que no tienen control posterior de constitucionalidad (Francia).

* El desarrollo de la responsabilidad del Estado legislador es jurisprudencial y sigue siendo jurisprudencial, a excepción de España que sí la regula por ley -aunque la jurisprudencia española no deja de llenar los grandes vacíos jurídicos-.

* Desde la gestación del artículo 90 de la Constitución Política de 1991, la noción de daño antijurídico e imputación se predica de todos los poderes del Estado. No sólo al Estado administrador, sino también, al Estado juez y al Estado legislador.

* En la Constitución Política de 1991 tenemos los siguientes soportes constitucionales de la responsabilidad del Estado legislador: la supremacía de la constitución, el robustecimiento del control de constitucionalidad, la constitucionalización de los principios fundamentales, el nuevo concepto de,soberanía, la regulación expresa de una cláusula general de la responsabilidad del Estado, y el concepto Zle Estado social de derecho.

* En Colombia existen antecedentes jurisprudenciales del Consejo de Estado y de la Corte Constitucional sobre la responsabilidad del Estado legislador.

\section{BIBLIOGRAFÍA}

HERNANDEZ, Alier. "Responsabilidad extracontractual del Estado colombiano". Bogotá:Revista Derechosy Valores, Universidad Militar Nueva Granada No 8, Diciembre de 2001.

ALVARO BUSTMANTE LEDESMA. La Responsabilidad Extracontractual del Estado. Bogotá: Editorial Leyer Ltda., 1999.
VALENCIA ZEA, Arturo y ORTÍZ MONSALVE, Alvaro. Derecho civil, T. III, $9^{\text {a }}$ Bogotá: Editorial, Temis, 1998.

ARENAS URIBE, Carolina y JMENEZ USCATEGUI, Mariangela. La responsabilidad del Estado por el hecho del legislador. Trabajo de Tesis. Bogotá: Pontificia Universidad Javeriana, 2001.

Consejo de Estado, Sección Tercera. Auto de 15 de mayo de 2003, Radicación: 76001-2331-000-2002-1912-01(23245),Actor: Bernardo Villalba Laytony Otro, C.P.:ALIEREDUARDO HERNÁNDEZ ENRÍQUEZ.

ConsejodeEstado, Sección Tercera. Sentenciade 26 de septiembre de 2002, Radicación número: 25000-23-26-000-1997-4458-01(20945), Actor: Municipio de Prado, C.P.: ALIER EDUARDO HERNÁNDEZ ENRÍQUEZ.

Consejo de Estado, Sección Tercera. Sentencia de $1^{\circ}$ de noviembre de 2001, C.P.: MARÍA ELENA GIRALDO GÓMEZ, Actor: Oswaldo Patascoy Martinez.

Consejo de Estado, Sala Plena. Sentencia de 25 de Agosto de 1998, Exp. IJ001, Actor: Vitelvina Rojas Robles, C.P.: JESÚS MARIA CARRILLO BALLESTEROS.

Consejo de Estado, Sala Plena. Sentencia de 8 de septiembre de 1998, Exp. IJ002, Actor: Leonor Judith Fandiño de Tarazona y otros, C.P.: DANIEL SUÁREZ HERNÁNDEZ.

Corte Constitucional, Sala Plena. Sentencia C038 del $1^{\circ}$ de febrero de 2006, Expediente D5839, Demandante: Félix Hoyos Lemus, M.P.: HUMBERTO ANTONIO SIERRA PORTO.

Corte Constitucional, Sala Plena. Sentencia C543 de 16 de octubre de 1996, Expediente D1286, Demandante: Hugo Alberto Marín, M.P.: CARLOS GAVIRIA DIAZ. 
QUINTERO ROJAS, German Eduardo. "De la responsabilidad del Estado legislador", Revista del programa de derecho, No. 8, 2004, Ibagué: Coruniversitaria.

MARTÍNEZ RAVE, Gilberto y MARTÍNEZ TAMAYO, Catalina. Responsabilidad civil extracontractual, $11^{\mathrm{a}} \mathrm{ed}$. Temis, 2003.

PENAGOS, Gustavo. El daño antijurídico, aplicación del principio iura novit curia. Bogotá: Ediciones librería doctrina y ley, 1997.

ESCOLA, Hector Jorge. Compendio de derecho administrativo, Vol.II. Buenos Aires: Ediciones Depalma, 1990.

TAMAYO JARAMILLO, Javier. De la responsabilidad civil, Tomo I. Bogotá: Temis, 1999.

CARRILLO BALLESTEROS, Jesus Maria. "Las principales doctrinas del Consejo de Estado colombiano". En A.A.V.V. Historia y perspectivas de la jurisdicción administrativa en Francia y en América Latina, Coloquio conmemorativo del bicentenario del Consejo de Estado francés. Bogotá: Temis, 1999.

AYALA, Jorge Enrique. Elementos de derecho administrativo, $1^{a}$ Edición. Bogotá: Ediciones Doctrina y Ley Ltda., 1999.
HENAO, Juan Carlos. El daño, análisis comparativo de la responsabilidad extracontractual del Estado en derecho colombiano y francés. Bogotá: Universidad Externado de Colombia, 1998.

HENAO, Juan Carlos. "Presentación general de la responsabilidad extracontractual del Estado en Colombia", en A.A.V.V. II Jornadas colombo-venezolana de derecho público, Bogotá, Universidad Externado de Colombia, 1996.

RODRIGUEZ R., Libardo. Derecho administrativo general y colombiano, $12^{\mathrm{a}}$ edición. Bogotá: Temis, 2000.

MORALES TÁMARA, Manuel Alberto. "Responsabilidad patrimonial del Estado legislador", A.A.V.V. II Jornadas de derecho constitucional y administrativo. Bogotá: Universidad Externado de Colombia, 2002.

FRANCO RODRÍGUEZ, Paola y GÓNGORA MERA, Manuel Eduardo. La responsabilidad del Estado legislador en los eventos de sentencias moduladas. Trabajo de Tesis. Bogotá: Pontificia Universidad Javeriana, 2001.

SAAVEDRA BECERRA, Ramiro. La responsabilidad extracontractual de la administración pública, $1^{\circ}$ Edición. Bogotá: Ediciones jurídicas Gustavo Ibáñez, 2005. 